\title{
An analysis of the associations between gender and metabolic syndrome components in Korean adults: a national cross-sectional study
}

\author{
Young-Mo Yang ${ }^{1}$, Byung-Cheul Shin ${ }^{2}$, Chihyoung Son ${ }^{3}$ and In-Hyuk Ha ${ }^{4^{*}}$ (D)
}

\begin{abstract}
Background: This study aimed to examine the associations between gender and the prevalence of metabolic syndrome (MS) components among Korean adults by age and body mass index (BMI) subgroups.

Methods: This study obtained data from the sixth Korea National Health and Nutrition Examination Survey 20132015, a cross-sectional and nationally representative survey conducted by the Korean Centers for Diseases Control and Prevention.

Results: Of the 11,136 subjects included in this study, there were 4627 (41.5\%) men and 6509 (58.5\%) women. Compared to women, men were at higher risks of hypertension (HTN) (odds ratio [OR], 1.508; 95\% confidence interval [Cl], 1.320-1.723), diabetes mellitus (DM) $(\mathrm{OR}, 1.638 ; 95 \% \mathrm{Cl}, 1.333-2.013)$, prediabetes $(\mathrm{OR}, 1.549 ; 95 \% \mathrm{Cl}$, 1.355-1.771), and hypertriglyceridemia $(\mathrm{OR}, 2.466 ; 95 \% \mathrm{Cl}, 2.097-2.900)$, but at lower risks of low high-density lipoprotein (HDL) (OR, 0.346; 95\% Cl, 0.307-0.390) and high waist circumference (WC) $(\mathrm{OR}, 0.780 ; 95 \% \mathrm{Cl}, 0.647-$ 0.940). Among subjects with $\mathrm{BMl}<25 \mathrm{~kg} / \mathrm{m}^{2}$, the risks of $\mathrm{HTN}, \mathrm{DM}$, prediabetes, and hypertriglyceridemia were higher in men than in women, whereas the risks of low HDL level and high WC were lower in men. Similarly, among subjects with $\mathrm{BMI} \geq 25 \mathrm{~kg} / \mathrm{m}^{2}$, compared to women, men were at higher risks of HTN, DM, prediabetes, and hypertriglyceridemia, but at lower risks of low HDL level.

Conclusions: The difference in the prevalence of MS components between men and women can be partially explained by the different effects of gender on the etiology of MS components. The results showed that gender was likely to contribute to an increase in the prevalence of MS components. HTN, DM, prediabetes, and hypertriglyceridemia were more prevalent in men than in women, whereas the prevalence of low HDL level and high WC were higher in women than in men. Similar results were found in subgroup analyses by age and BMI.
\end{abstract}

Keywords: Metabolic syndrome, Koreans, Gender, Cross-sectional study, Menopause

\section{Background}

Metabolic syndrome (MS) is a cluster of metabolic abnormalities. The MS-associated factors including waist circumference (WC), triglyceride (TG) levels, highdensity lipoprotein (HDL) cholesterol levels, hypertension (HTN), and fasting blood glucose (FBG) levels are classic risk factors for cardiovascular disease and

\footnotetext{
* Correspondence: hanihata@gmail.com

${ }^{4}$ Jaseng Spine and Joint Research Institute, Jaseng Medical Foundation, 3F JS Tower, 538 Gangnam-daero, Gangnam-gu, Seoul 06110, Republic of Korea Full list of author information is available at the end of the article
}

diabetes mellitus (DM) [1, 2]. The prevalence rates of MS varied by geographical regions; however, it was estimated that approximately $25 \%$ of adults had MS in most countries [3-5].

Over the past decades, the prevalence of MS rapidly increased in Asian countries including Korea [5-8]. Li and colleagues reported that the overall prevalence rate of MS in China was $24.2 \%$ (24.6\% in men and $23.8 \%$ in women) [5]. In Eastern India, the overall prevalence rate of MS was $33.5 \%$ (24.9\% in men and $42.3 \%$ in women)

(c) The Author(s). 2019 Open Access This article is distributed under the terms of the Creative Commons Attribution 4.0 International License (http://creativecommons.org/licenses/by/4.0/), which permits unrestricted use, distribution, and reproduction in any medium, provided you give appropriate credit to the original author(s) and the source, provide a link to the Creative Commons license, and indicate if changes were made. The Creative Commons Public Domain Dedication waiver (http://creativecommons.org/publicdomain/zero/1.0/) applies to the data made available in this article, unless otherwise stated. 
[8]. In Korea, MS was reported in $26.9 \%$ of the entire population (30.0\% in men and $24.6 \%$ in women) [9].

Additionally, there was a gender-related disparity in the prevalence of MS. It tended to occur more frequently in men than in women. However, a reversed trend was shown among old adults, as reported in several studies $[1,5,10-13]$. This tendency may be explained by the gender differences in the prevalence of MS-related risk factors. According to previous studies, high blood pressure (BP), high level of TG, and elevated level of FBG were more prevalent in men, whereas low HDL level and high WC were more prevalent in women $[4,10]$.

Consequently, gender as an independent risk factor for the components of MS may play an important role in determining the prevalence of MS in men and women. However, limited studies investigated the relationships between gender and the prevalence of MS components among Korean adults [10]. Therefore, this study aims to examine the associations between gender and the prevalence of MS components in Korean adults by age and body mass index (BMI) subgroups.

\section{Methods}

\section{Study population}

This study obtained data from the sixth Korea National Health and Nutrition Examination Survey (KNHANES VI) (2013-2015), a cross-sectional and nationally representative survey conducted by the Korean Centers for Diseases Control and Prevention (CDC). The KNHANES data were collected every year from 3840 individuals randomly selected from 192 regions in Korea using a stratified multi-stage probability sampling design. The KNHANES consisted of a health interview, a health examination, and a nutrition survey. The data were obtained through household interviews, and the standardized physical examinations were carried out at mobile examination centers. Written informed consent was obtained from all study participants. This study was approved by the Korean CDC Institutional Review Board. All study subjects were aged $\geq 19$ years. Only subjects without missing data on hypertension, diabetes mellitus, hypertriglyceridemia, and low HDL level were eligible for this study. Ultimately, 11, 136 adults (4627 men and 6509 women) were included in this study (Fig. 1).

\section{Blood tests}

Fasting serum glucose, triglyceride, and HDL cholesterol levels were measured after an overnight (at least 8-12 h) fasting period. Subjects were categorized into three groups based on the measured fasting glucose levels: normal glucose level $(<100 \mathrm{mg} / \mathrm{dL})$, impaired fasting glucose or prediabetes $(100-125 \mathrm{mg} / \mathrm{dL})$, and DM $(\geq 126$ $\mathrm{mg} / \mathrm{dL}$ ) [14]. All subjects with a known diagnosis of DM treated with antiglycemic agents and/or insulin were assigned to the DM group, regardless of their fasting glucose levels. Hypertriglyceridemia was defined as fasting triglyceride level $\geq 200 \mathrm{mg} / \mathrm{dL}$, which corresponds to a high or very high TG level according to the National Cholesterol Education Program Adult Treatment Panel III (NCEP ATP III) guidelines [15]. Low HDL cholesterol

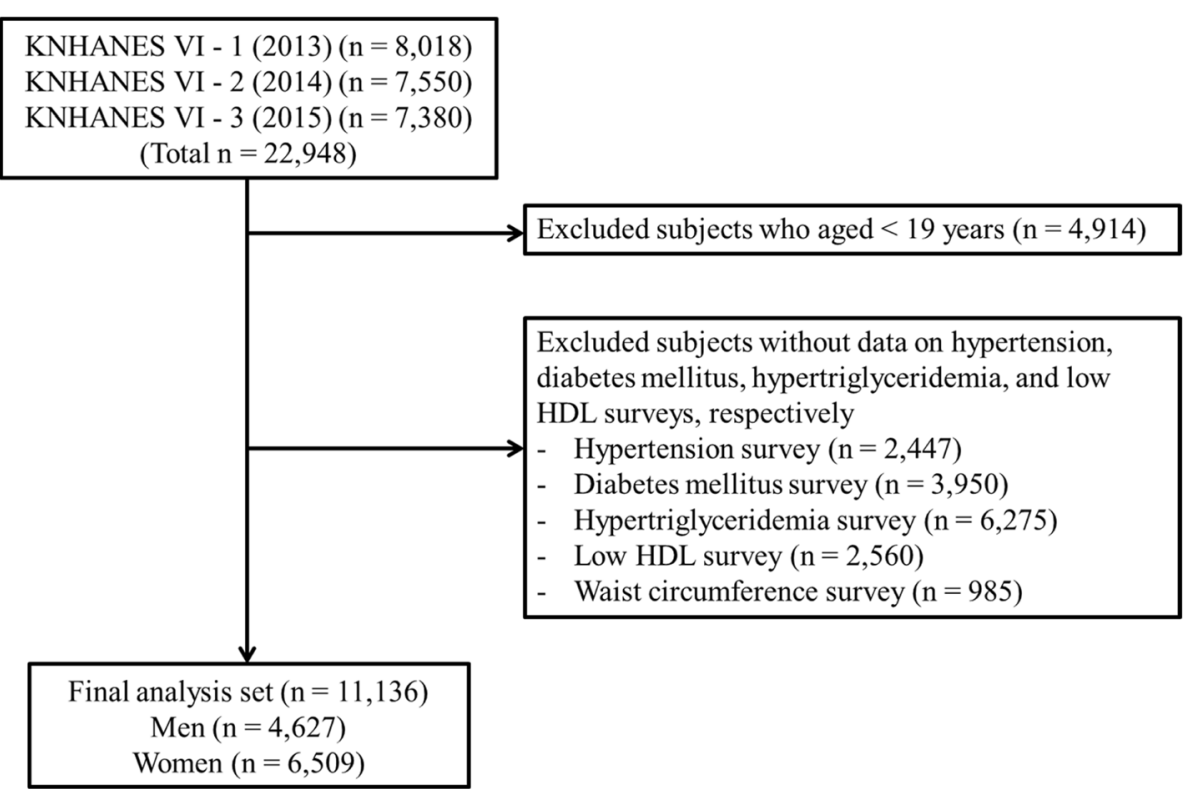

Fig. 1 Subject selection from the Korea National Health and Nutrition Examination Survey 2013-2015. KNHANES, Korea national health and nutrition examination survey; HDL, high-density lipoprotein 
level was defined as HDL level $<40 \mathrm{mg} / \mathrm{dL}$ for men and HDL level $<50 \mathrm{mg} / \mathrm{dL}$ for women [15].

\section{Blood pressure measurements}

Study subjects were seated for at least $5 \mathrm{~min}$ before the measurement of blood pressure on the right arm with a standard mercury sphygmomanometer. Three measurements were taken for each subject at 5-min intervals. The average of the second and third measurements was used in the analysis. Hypertension was defined as systolic blood pressure (SBP) $\geq 140 \mathrm{mmHg}$, or diastolic blood pressure (DBP) $\geq 90 \mathrm{mmHg}$, or if subjects were under antihypertensive therapy [16].

\section{Body mass index and waist circumference}

Body weight and height were measured to the nearest $0.1 \mathrm{~kg}$ and $0.1 \mathrm{~cm}$. Study subjects were required to wear light indoor clothing without shoes. BMI was computed by dividing weight in kilograms by height in meters squared $\left(\mathrm{kg} / \mathrm{m}^{2}\right)$. Subjects were categorized into three groups by the BMI: underweight (BMI $<18.5 \mathrm{~kg} / \mathrm{m}^{2}$ ), normal weight (BMI: $18.5-25.0 \mathrm{~kg} / \mathrm{m}^{2}$ ), and overweight or obese (BMI $\geq 25.0 \mathrm{~kg} / \mathrm{m}^{2}$ ) [17]. Waist circumference (WC) measurement was taken to the nearest $0.1 \mathrm{~cm}$ in a horizontal plane at the midpoint between the iliac crest and the lower rib. High WC was defined as $W C \geq 90 \mathrm{~cm}$ for men and $W C \geq 85 \mathrm{~cm}$ for women according to the criteria for abdominal obesity recommended by the Korean Society for the Study of Obesity [18].

\section{Other variables}

Self-reported age, socioeconomic characteristics (i.e., household income and educational level), and lifestyle risk factors (i.e., smoking status, alcohol consumption, and sedentary time) were collected from the questionnaire survey. The average monthly household income was categorized by quartiles into low, lower middle, higher middle, and high groups. Educational level was categorized into four groups: elementary school graduation or lower, middle school graduation, high school graduation, and college graduation or higher. By their self-reported smoking status, subjects were categorized in to current smokers (who had smoked $\geq 100$ cigarettes and kept smoking at the time of the survey), or non-/ex-smokers (who had never smoked or had smoked $<100$ cigarettes in their lifetime/ those who had smoked $\geq 100$ cigarettes, but did not smoke at the time of the survey). Alcohol consumption was dichotomized into zero consumption and non-zero consumption. Sedentary time was dichotomized using a cut-off of 7 h/day [19].

\section{Statistical analysis}

SAS version 9.4 (SAS Institute Inc., Cary, NC, USA) survey procedure was utilized for all statistical analyses.
The KNHANES sampling weights were applied to obtain nationally representative estimates. Data analysis was conducted by applying a complex sampling design with stratified variables, cluster variables, and weighted variables. $P$-value of 0.05 was used to define statistical significance. Subgroup analyses were performed by gender and age subgroups ( $19-54$ years and $\geq 55$ years). Categorical variables were presented as frequency and percentage (\%), whereas continuous variables were reported as mean and standard deviation. Chi-square tests and independent $\mathrm{t}$-test were applied wherever appropriate. Multivariate logistic regression analysis was used to evaluate the impact of gender (using women as the reference group) on the prevalence of MS components by age and BMI subgroups. The results were reported as odds ratios (ORs) and 95\% confidence intervals (CIs).

\section{Results}

Of the 11,136 subjects included in this study, there were 4627 men (41.5\%) and 6509 women (58.5\%). The characteristics of these participants are summarized in Table 1. Compared to women, the prevalence of HTN, DM, prediabetes, hypertriglyceridemia, and high WC were higher in men. However, the prevalence of low HDL level was lower in men than in women. All the differences were statistically significant $(p<0.0001$ for all). Similar results were shown in subgroup analyses by age groups. Furthermore, aside from the MS components, there were statistically significant differences in other variables between men and women.

To determine the associations between gender and the prevalence of MS components in all subjects, logistic regression analysis was performed. The results are presented in Table 2. Compared to women, men were at higher risks of HTN, DM, prediabetes, and hypertriglyceridemia, but lower risks of low HDL level and high WC. In subjects with BMI $<25 \mathrm{~kg} / \mathrm{m}^{2}$, the risks of developing HTN, DM, prediabetes, and hypertriglyceridemia were higher in men than in women, whereas the risks of low HDL level and high WC were lower in men. Similarly, in subjects with BMI $\geq 25 \mathrm{~kg} / \mathrm{m}^{2}$, the risks of HTN, $\mathrm{DM}$, prediabetes, and hypertriglyceridemia were higher in men than in women, whereas the risk of low HDL level was lower in men.

The results of the logistic regression analysis among subjects aged 19-54 years are presented in Table 3 . Compared to women, men were at higher risks of HTN, prediabetes, and hypertriglyceridemia, but lower risks of low HDL level and high WC. No significant difference was found in DM between men and women. In subjects with BMI $<25 \mathrm{~kg} / \mathrm{m}^{2}$, the risks of HTN, DM, prediabetes, and hypertriglyceridemia were higher in men than in women, whereas the risks of low HDL level was lower in men. In subjects with $\mathrm{BMI} \geq 25 \mathrm{~kg} / \mathrm{m}^{2}$, compared to 


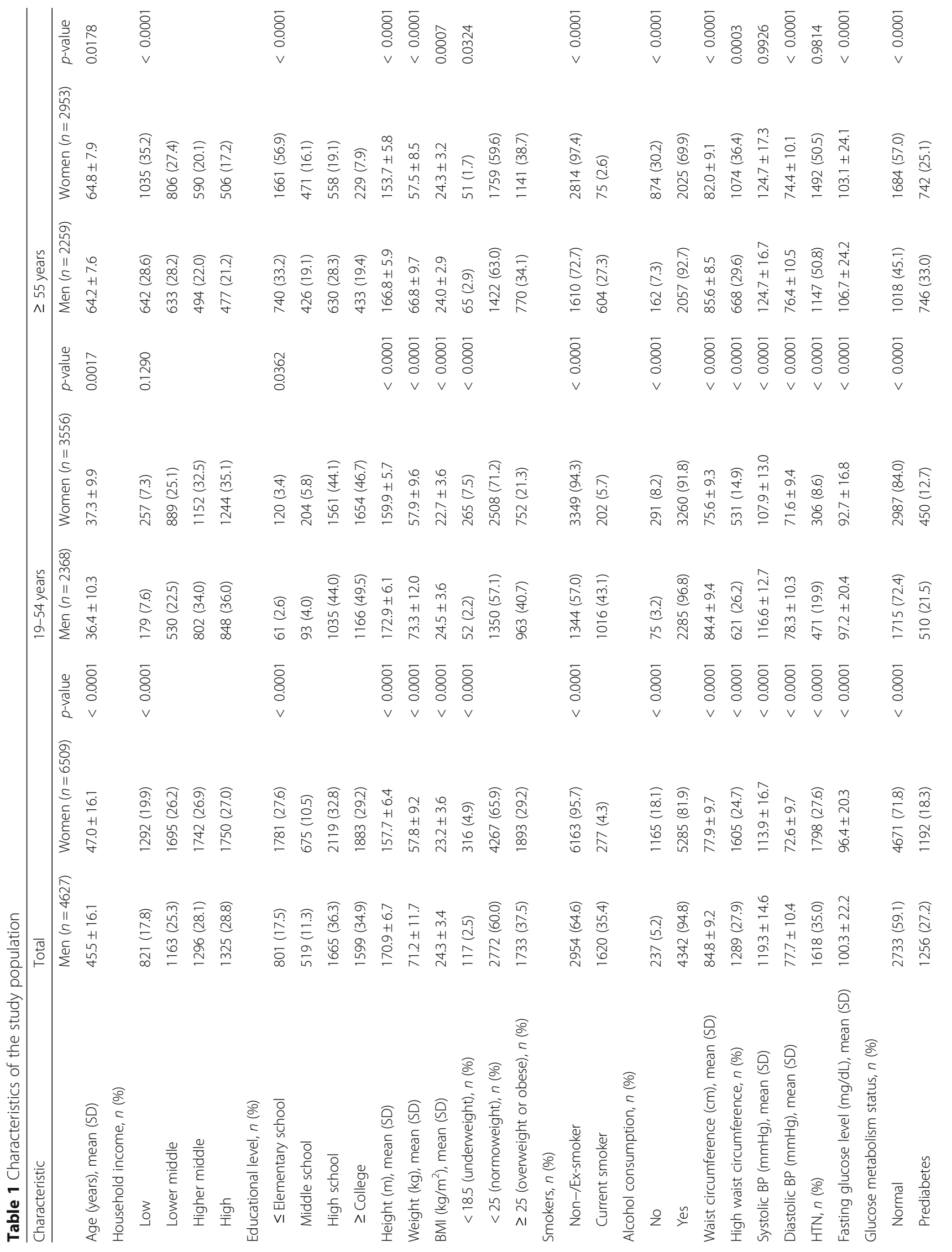




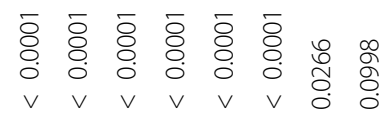

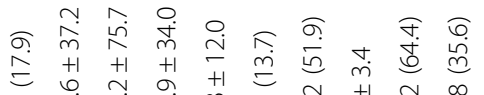

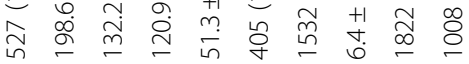

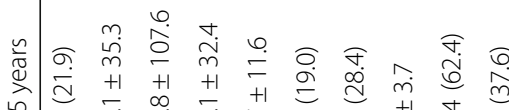

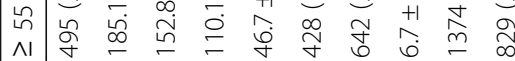

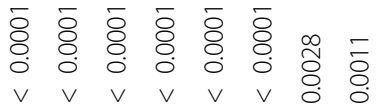

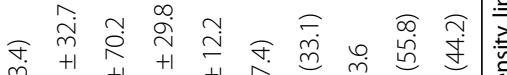

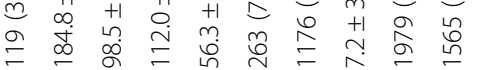

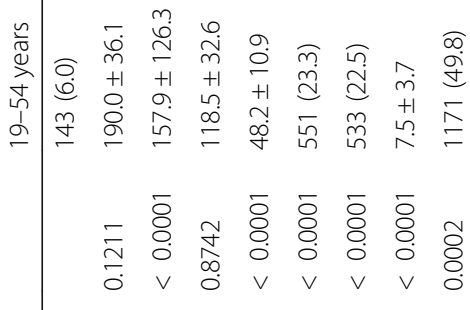

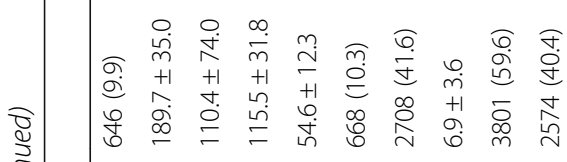

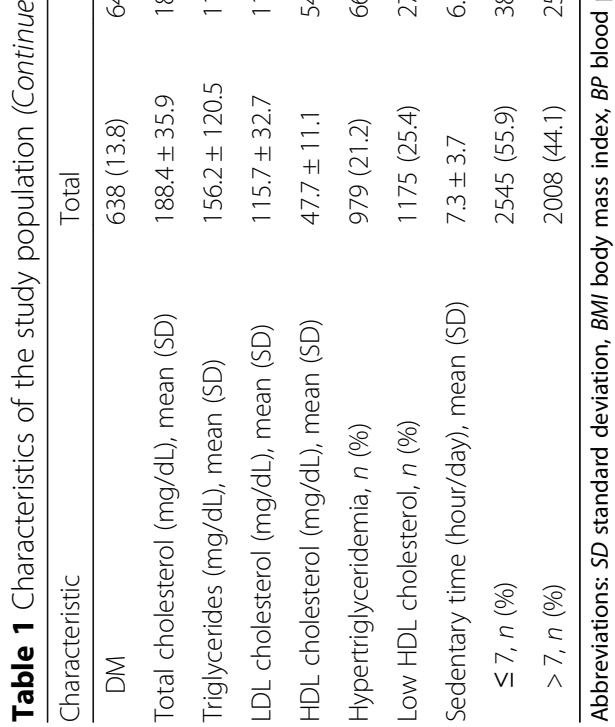


Table 2 Odds ratios for the prevalence of metabolic syndrome components among study subjects

\begin{tabular}{|c|c|c|c|c|c|c|c|c|}
\hline $\begin{array}{l}\text { Metabolic syndrome } \\
\text { components }\end{array}$ & $\begin{array}{l}\text { Unadjusted OR } \\
(95 \% \mathrm{Cl})\end{array}$ & $p$-value & $\begin{array}{l}\text { Adjusted OR } \\
(95 \% \mathrm{Cl})\end{array}$ & $p$-value & $\begin{array}{l}\text { Adjusted OR }(95 \% \mathrm{Cl}) \\
\text { for } \mathrm{BMl}<25 \mathrm{~kg} / \mathrm{m}^{2 \mathrm{a}}\end{array}$ & $p$-value & $\begin{array}{l}\text { Adjusted OR }(95 \% \mathrm{Cl}) \\
\text { for BMl } \geq 25 \mathrm{~kg} / \mathrm{m}^{2 a}\end{array}$ & $p$-value \\
\hline$\overline{H_{T} N^{b}}$ & $\begin{array}{l}1.373 \\
(1.256-1.501)\end{array}$ & $<0.0001$ & $\begin{array}{l}1.508 \\
(1.320-1.723)\end{array}$ & $<0.0001$ & $1.331(1.111-1.595)$ & 0.0020 & $1.716(1.383-2.131)$ & $<0.0001$ \\
\hline $\mathrm{DM}^{\mathrm{c}}$ & $\begin{array}{l}1.543 \\
(1.333-1.785)\end{array}$ & $<0.0001$ & $\begin{array}{l}1.638 \\
(1.333-2.013)\end{array}$ & $<0.0001$ & $1.847(1.425-2.395)$ & $<0.0001$ & $1.444(1.060-1.968)$ & 0.0201 \\
\hline Prediabetes $^{c}$ & $\begin{array}{l}1.708 \\
(1.536-1.899)\end{array}$ & $<0.0001$ & $\begin{array}{l}1.549 \\
(1.355-1.771)\end{array}$ & $<0.0001$ & $1.760(1.468-2.111)$ & $<0.0001$ & $1.337(1.072-1.668)$ & 0.0102 \\
\hline Hypertriglyceridemia $^{d}$ & $\begin{array}{l}2.785 \\
(2.466-3.146)\end{array}$ & $<0.0001$ & $\begin{array}{l}2.466 \\
(2.097-2.900)\end{array}$ & $<0.0001$ & $2.071(1.639-2.617)$ & $<0.0001$ & $3.060(2.449-3.824)$ & $<0.0001$ \\
\hline Low HDL ${ }^{e}$ & $\begin{array}{l}0.503 \\
(0.458-0.553)\end{array}$ & $<0.0001$ & $\begin{array}{l}0.346 \\
(0.307-0.391)\end{array}$ & $<0.0001$ & $0.369(0.313-0.435)$ & $<0.0001$ & $0.304(0.251-0.368)$ & $<0.0001$ \\
\hline High waist circumference ${ }^{f}$ & $\begin{array}{l}1.288 \\
(1.167-1.421)\end{array}$ & $<0.0001$ & $\begin{array}{l}0.780 \\
(0.647-0.940)\end{array}$ & 0.0093 & $0.705(0.534-0.930)$ & 0.0136 & 0.977 (0.800-1.193) & 0.8160 \\
\hline
\end{tabular}

Notes: Odds ratios with adjustments using logistic regression models

${ }^{a}$ Not adjusted for BMI

${ }^{\mathrm{b}}$ Adjusted for age, household income, educational level, BMI, smoking status, alcohol consumption, DM, prediabetes, hypertriglyceridemia, low HDL level, high waist circumference, and sedentary time

'Adjusted for age, household income, educational level, BMI, smoking status, alcohol consumption, HTN, hypertriglyceridemia, low HDL level, high waist circumference, and sedentary time

${ }^{\mathrm{d}}$ Adjusted for age, household income, educational level, BMI, smoking status, alcohol consumption, HTN, DM, prediabetes, low HDL level, high waist circumference, and sedentary time

${ }^{\text {e}}$ Adjusted for age, household income, educational level, BMI, smoking status, alcohol consumption, HTN, DM, prediabetes, hypertriglyceridemia, high waist circumference, and sedentary time

${ }^{f}$ Adjusted for age, household income, educational level, BMI, smoking status, alcohol consumption, HTN, DM, prediabetes, hypertriglyceridemia, low HDL level, and sedentary time

Abbreviations: HTN hypertension, DM diabetes mellitus, $H D L$ high-density lipoprotein, $B M I$ body mass index

Table 3 Odds ratios for the prevalence of metabolic syndrome components among subjects aged 19-54 years

\begin{tabular}{|c|c|c|c|c|c|c|c|c|}
\hline $\begin{array}{l}\text { Metabolic syndrome } \\
\text { components }\end{array}$ & $\begin{array}{l}\text { Unadjusted OR } \\
(95 \% \mathrm{Cl})\end{array}$ & $p$-value & $\begin{array}{l}\text { Adjusted OR } \\
(95 \% \mathrm{Cl})\end{array}$ & $p$-value & $\begin{array}{l}\text { Adjusted OR }(95 \% \mathrm{Cl}) \\
\text { for } \mathrm{BMl}<25 \mathrm{~kg} / \mathrm{m}^{2 \mathrm{a}}\end{array}$ & $p$-value & $\begin{array}{l}\text { Adjusted OR }(95 \% \mathrm{Cl}) \\
\text { for } \mathrm{BMI} \geq 25 \mathrm{~kg} / \mathrm{m}^{2 \mathrm{a}}\end{array}$ & $p$-value \\
\hline $\mathrm{HTN}^{\mathrm{b}}$ & $\begin{array}{l}2.577 \\
(2.195-3.026)\end{array}$ & $<0.0001$ & $\begin{array}{l}1.987 \\
(1.615-2.445)\end{array}$ & $<0.0001$ & $1.690(1.236-2.312)$ & 0.0011 & 2.209 (1.593-3.063) & $<0.0001$ \\
\hline $\mathrm{DM}^{\mathrm{c}}$ & $\begin{array}{l}2.169 \\
(1.633-2.881)\end{array}$ & $<0.0001$ & $\begin{array}{l}1.421 \\
(0.974-2.073)\end{array}$ & 0.0686 & $1.909(1.163-3.133)$ & 0.0106 & $1.067(0.622-1.831)$ & 0.8129 \\
\hline Prediabetes $^{c}$ & $\begin{array}{l}1.939 \\
(1.665-2.257)\end{array}$ & $<0.0001$ & $\begin{array}{l}1.417 \\
(1.169-1.718)\end{array}$ & 0.0004 & $1.785(1.377-2.315)$ & $<0.0001$ & $1.094(0.812-1.475)$ & 0.5545 \\
\hline Hypertriglyceridemia $^{\mathrm{d}}$ & $\begin{array}{l}3.879 \\
(3.286-4.579)\end{array}$ & $<0.0001$ & $\begin{array}{l}3.234 \\
(2.582-4.051)\end{array}$ & $<0.0001$ & $3.238(2.317-4.524)$ & $<0.0001$ & $3.803(2.755-5.250)$ & $<0.0001$ \\
\hline Low HDL ${ }^{e}$ & $\begin{array}{l}0.581 \\
(0.510-0.661)\end{array}$ & $<0.0001$ & $\begin{array}{l}0.311 \\
(0.261-0.371)\end{array}$ & $<0.0001$ & $0.375(0.298-0.472)$ & $<0.0001$ & $0.243(0.183-0.321)$ & $<0.0001$ \\
\hline High waist circumference ${ }^{f}$ & $\begin{array}{l}1.937 \\
(1.691-2.218)\end{array}$ & $<0.0001$ & $\begin{array}{l}0.688 \\
(0.517-0.915)\end{array}$ & 0.0103 & $0.673(0.398-1.137)$ & 0.1383 & $0.946(0.728-1.230)$ & 0.6801 \\
\hline
\end{tabular}

Notes: Odds ratios with adjustments using logistic regression models

${ }^{a}$ Not adjusted for BMI

${ }^{\mathrm{b}}$ Adjusted for age, household income, educational level, BMI, smoking status, alcohol consumption, DM, prediabetes, hypertriglyceridemia, low HDL level, high waist circumference, and sedentary time

'Adjusted for age, household income, educational level, BMI, smoking status, alcohol consumption, HTN, hypertriglyceridemia, low HDL level, high waist circumference, and sedentary time

${ }^{\mathrm{d}}$ Adjusted for age, household income, educational level, BMI, smoking status, alcohol consumption, HTN, DM, prediabetes, low HDL level, high waist circumference, and sedentary time

eAdjusted for age, household income, educational level, BMI, smoking status, alcohol consumption, HTN, DM, prediabetes, hypertriglyceridemia, high waist circumference, and sedentary time

${ }^{f}$ Adjusted for age, household income, educational level, BMI, smoking status, alcohol consumption, HTN, DM, prediabetes, hypertriglyceridemia, low HDL level, and sedentary time

Abbreviations: HTN hypertension, DM diabetes mellitus, HDL high-density lipoprotein, BMI body mass index 
women, men were at higher risks of HTN and hypertriglyceridemia but lower risks of low HDL level.

Finally, the results of the logistic regression analysis among subjects aged $\geq 55$ years are presented in Table 4 . Men were at higher risks of HTN, DM, prediabetes, and hypertriglyceridemia, but lower risks for low HDL level than women. In subjects with $\mathrm{BMI}<25 \mathrm{~kg} / \mathrm{m}^{2}$, the risks of HTN, DM, and prediabetes were higher in men than in women, whereas the risks of low HDL level was lower in men. In subjects with BMI $\geq 25 \mathrm{~kg} / \mathrm{m}^{2}$, compared to women, men were at higher risks of DM, prediabetes, and hypertriglyceridemia but lower risks of low HDL level.

\section{Discussion}

In this study, we investigated the associations between gender and the prevalence of MS components among Korean adults using data from the KNHANES VI. The results showed that gender appeared to be an independent predictor of the prevalence of the most MS components. While HTN, DM, prediabetes, and hypertriglyceridemia were more prevalent in men than in women, the prevalence of low HDL level and high WC were higher in women than in men. However, it should be noted that the definitions of low HDL level and high WC differ between men and women. Stricter definitions were set in women than in men, which may partially explain the higher prevalence rates of low HDL level and high WC found in women. Similar results were found in subgroup analyses by age and BMI. The differences in the prevalence of MS components may be related to the sex-related characteristics (e.g., biological traits and functional features) and gender-associated determinants (e.g., psychological and cultural habits) [1]. Importantly, the changes in hormone level during and after menopause may contribute to the gender differences in the prevalence of MS components in older age population [1,20,21]. Since the studies on the associations between gender and the prevalence of MS components by age and BMI have been rarely implemented in Korea, it is meaningful in that this study could be utilized as a better knowledge on the development of health strategies for managing MS components according to gender.

The most prominent differences between men and women were the prevalence of hypertriglyceridemia and low HDL level. According to a previous study using the KNHANES data between 1998 and 2010, hypertriglyceridemia and low HDL level were the most prevalent dyslipidemia in Korean adults [22]. In the present study, the overall prevalence of hypertriglyceridemia was 2.466 times higher in men than in women. This trend was more prominent in subjects aged between 19 and 54 years (3.234 times) than those aged $\geq 55$ years (1.614 times). The overall prevalence of low HDL level was 2.890 times higher in women than in men. Similarly, this trend was more prominent in subjects aged between 19 and 54 years ( 3.215 times) than those aged $\geq 55$ years (2.611 times). The high prevalence of the two conditions in Korean adults may be associated with the high

Table 4 Odds ratios for the prevalence of metabolic syndrome components among subjects aged $\geq 55$ years

\begin{tabular}{|c|c|c|c|c|c|c|c|c|}
\hline $\begin{array}{l}\text { Metabolic syndrome } \\
\text { components }\end{array}$ & $\begin{array}{l}\text { Unadjusted OR } \\
(95 \% \text { Cl) }\end{array}$ & $p$-value & $\begin{array}{l}\text { Adjusted OR } \\
(95 \% \mathrm{Cl})\end{array}$ & $p$-value & $\begin{array}{l}\text { Adjusted OR }(95 \% \mathrm{Cl}) \\
\text { for } \mathrm{BMI}<25 \mathrm{~kg} / \mathrm{m}^{2 \mathrm{a}}\end{array}$ & $p$-value & $\begin{array}{l}\text { Adjusted OR }(95 \% \mathrm{Cl}) \\
\text { for } \mathrm{BMI} \geq 25 \mathrm{~kg} / \mathrm{m}^{2 \mathrm{a}}\end{array}$ & $p$-value \\
\hline $\mathrm{HTN}^{\mathrm{b}}$ & $\begin{array}{l}1.002 \\
(0.881-1.139)\end{array}$ & 0.9814 & $\begin{array}{l}1.295 \\
(1.095-1.532)\end{array}$ & 0.0026 & $1.380(1.116-1.707)$ & 0.0030 & 1.185 (0.895-1.569) & 0.2350 \\
\hline $\mathrm{DM}^{c}$ & $\begin{array}{l}1.520 \\
(1.272-1.818)\end{array}$ & $<0.0001$ & $\begin{array}{l}1.789 \\
(1.430-2.240)\end{array}$ & $<0.0001$ & $1.935(1.454-2.576)$ & $<0.0001$ & $1.696(1.203-2.391)$ & 0.0026 \\
\hline Prediabetes $^{\complement}$ & $\begin{array}{l}1.662 \\
(1.437-1.923)\end{array}$ & $<0.0001$ & $\begin{array}{l}1.697 \\
(1.421-2.026)\end{array}$ & $<0.0001$ & $1.770(1.397-2.242)$ & $<0.0001$ & $1.615(1.194-2.185)$ & 0.0019 \\
\hline Hypertriglyceridemia ${ }^{d}$ & $\begin{array}{l}1.743 \\
(1.467-2.072)\end{array}$ & $<0.0001$ & $\begin{array}{l}1.614 \\
(1.280-2.036)\end{array}$ & $<0.0001$ & $1.143(0.816-1.603)$ & 0.4360 & $2.353(1.701-3.255)$ & $<0.0001$ \\
\hline Low HDL ${ }^{e}$ & $\begin{array}{l}0.402 \\
(0.352-0.460)\end{array}$ & $<0.0001$ & $\begin{array}{l}0.383 \\
(0.325-0.451)\end{array}$ & $<0.0001$ & $0.368(0.295-0.458)$ & $<0.0001$ & $0.382(0.293-0.499)$ & $<0.0001$ \\
\hline High waist circumference ${ }^{f}$ & $\begin{array}{l}0.772 \\
(0.670-0.889)\end{array}$ & 0.0003 & $\begin{array}{l}0.872 \\
(0.695-1.095)\end{array}$ & 0.2383 & $0.816(0.595-1.119)$ & 0.2059 & $1.051(0.772-1.432)$ & 0.7502 \\
\hline
\end{tabular}

Notes: Odds ratios with adjustments using logistic regression models

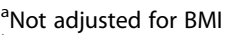

${ }^{\mathrm{b}}$ Adjusted for age, household income, educational level, BMI, smoking status, alcohol consumption, DM, prediabetes, hypertriglyceridemia, low HDL level, high waist circumference, and sedentary time

${ }^{\mathrm{C}}$ Adjusted for age, household income, educational level, BMI, smoking status, alcohol consumption, HTN, hypertriglyceridemia, low HDL level, high waist circumference, and sedentary time

${ }^{\mathrm{d}}$ Adjusted for age, household income, educational level, BMI, smoking status, alcohol consumption, HTN, DM, prediabetes, low HDL level, high waist circumference, and sedentary time

${ }^{\mathrm{e}}$ Adjusted for age, household income, educational level, BMI, smoking status, alcohol consumption, HTN, DM, prediabetes, hypertriglyceridemia, high waist circumference, and sedentary time

${ }^{f}$ Adjusted for age, household income, educational level, BMI, smoking status, alcohol consumption, HTN, DM, prediabetes, hypertriglyceridemia, low HDL level, and sedentary time

Abbreviations: HTN hypertension, DM diabetes mellitus, HDL high-density lipoprotein, $B M I$ body mass index 
carbohydrate diet in Korea (e.g. rice) [22, 23]. According to a review study investigating the effect of carbohydrate consumption on metabolic parameters in diabetic patients, high intake of carbohydrate was associated with higher serum triglyceride levels and lower HDL levels [24]. Similar results were reported in a cross-sectional study of older women [25]. While abdominal obesity assessed by BMI and WC was negatively associated with HDL levels, it was positively associated with triglyceride levels [22, 26]. This is consistent with our findings, where a higher prevalence of hypertriglyceridemia and low HDL level were observed among overweight/obese subjects with $\mathrm{BMI} \geq 25 \mathrm{~kg} / \mathrm{m}^{2}$ compared to their counterparts, irrespective of gender.

To explore the effect of estrogen on the prevalence of MS components, study subjects were categorized into two groups by age using a cut-off of 55 years, at which a majority of Korean women would have reached menopause. The gender differences in the prevalence of hypertriglyceridemia and low HDL level became smaller among subjects aged $\geq 55$ years compared to their counterparts. However, substantial gender differences in the prevalence of hypertriglyceridemia and low HDL level still existed. Therefore, changes in the hormonal level were not the sole reason for the gender differences in the prevalence of hypertriglyceridemia and low HDL level. This tendency may also be associated with some gender-linked disparities such as different patterns of nutrition intake, lifestyle, or stress and different behaviors between men and women [21].

The overall prevalence of DM was 1.638 times higher in men than in women. While the pattern was observed in both subgroups by BMI, the gender differences were smaller among overweight/obese subjects compared to their counterparts. This is consistent with the findings of a previous study conducted in Uganda [27], in which the authors reported that while no correlation was found between BMI and the risk of type $2 \mathrm{DM}$ among men, the prevalence of DM in women significantly increased with BMI. More specifically, over $70 \%$ obese women were diagnosed with DM compared to $25 \%$ of women with $\mathrm{BMI}<20 \mathrm{~kg} / \mathrm{m}^{2}$ [27]. In addition, according to the Jackson Heart Study, abdominal obesity is associated with an increased fasting plasma glucose level and a higher prevalence of type $2 \mathrm{DM}$, and the correlation is stronger in women than in men $[28,29]$.

Interestingly, gender differences in the prevalence of DM increased in subjects aged $\geq 55$ years compared to their counterparts. Additionally, this tendency was more prominent among subjects with $B M I \geq 25 \mathrm{~kg} / \mathrm{m}^{2}$. This may be partially attributed to the frequent use of hormone replacement therapy (HRT) among postmenopausal women [30]. After menopause, estrogen deficiency would increase the risk of type $2 \mathrm{DM}$ in women due to the changes in insulin secretion, insulin sensitivity, and glucose effectiveness [28, 31]. Testosterone depletion would increase the risks of hyperglycemia and DM in men via its impact on insulin resistance and visceral adiposity $[28,32]$. Sex hormone therapies can reduce, to a certain extent, the risks of hyperglycemia and type $2 \mathrm{DM}$ in men and women [31,33-35]. Thus, the frequent use of HRT in postmenopausal women is likely to decrease the risks of DM, leading to relatively increased ORs among subjects aged $\geq 55$ years, especially those with $\mathrm{BMI} \geq 25 \mathrm{~kg} / \mathrm{m}^{2}$. However, the positive effects of estrogen and testosterone on glucose homeostasis may be expected within their physiological windows [28].

The overall prevalence of HTN was 1.508 times higher in men than in women. The gender difference was more pronounced in the younger age group. These results were consistent with the German Health Examination Survey study. The German study reported while the prevalence of HTN was 19.5 and $11.6 \%$ among men and women, respectively, in the 18-54 years age group, the gender differences were smaller among those aged 5579 years $(60.6 \%$ in men vs $61.5 \%$ in women) [36]. This can be explained by the changes in the estrogen levels after menopause [37]. Estrogen has a protective effect on the cardiovascular system. Estrogen directly activates the nitric oxide synthase in the endothelial cells and may recover and replace the damaged endothelial cells, which ultimately leads to vasodilation. Indirectly, estrogen also has a positive effect on the serum lipid levels through the receptor-mediated activation of the hepatic genes (e.g., Apo-protein genes) [37]. Moreover, estrogen and ageing may affect salt sensitivity, which is related to blood pressure regulation. After menopause, women become more salt-sensitive, thus more prone to high blood pressure [38].

Additionally, among subjects aged between 19 and 54 years, the disparity in the prevalence of HTN between men and women was more distinct among those with BMI $\geq 25 \mathrm{~kg} / \mathrm{m}^{2}$. This tendency may be partially explained by the difference in the pattern of fat disposition between men and women. Fat accumulation in women tends to appear more frequently in the lower body areas such as the gluteal site, whereas men show the tendency to accumulate fat in the intra-abdominal sites [39]. This result is likely to contribute to the differences in the prevalence of HTN among this age group because visceral fat is positively related with HTN and insulin resistance [40, 41]. However, this tendency disappeared among subjects aged $\geq 55$ years. This may be associated with estrogen deficiency and the accumulation of fat after menopause in women.

There are some limitations warrant mentioning. First, the cross-sectional design of this study made it difficult to conclude a causal inference between gender and the 
prevalence of MS components. Second, many variables measured at a single time point were used to assess the effects of gender on the prevalence of MS components, which would have a negative impact on data accuracy. Third, the sociodemographic characteristics of the study population were collected through the survey; thus, this might draw recall bias. Finally, the overall prevalence of MS components was likely to be underestimated because we excluded subjects with incomplete information on MS components. However, this process was unlikely to have a significant impact on the study results because it is highly possible that the missingness occurred at random.

\section{Conclusions}

The differences in the prevalence of MS between men and women can be partially explained by the different effects of gender on MS components. The results showed that gender was likely to contribute to an increased prevalence of MS components. HTN, DM, prediabetes, and hypertriglyceridemia were more prevalent in men than in women, whereas the prevalence of low HDL level and high WC were higher in women than in men. Similar results were observed in subgroup analysis by age and BMI. This trend was attenuated after women reached menopausal age.

\section{Abbreviations}

BMI: Body mass index; BP: Blood pressure; CDC: Centers for Diseases Control and Prevention; Cl: Confidence interval; DBP: Diastolic blood pressure; DM: Diabetes mellitus; FBG: Fasting blood glucose; HDL: High-density lipoprotein; HRT: Hormone replacement therapy; HTN: Hypertension; KNHANES: Korea National Health and Nutrition Examination Survey; MS: Metabolic syndrome; NCEP ATP III: National Cholesterol Education Program Adult Treatment Panel III; ORs: Odds ratios; SBP: Systolic blood pressure; TG: Triglyceride; WC: Waist circumference

\section{Acknowledgements}

Not applicable.

\section{Authors' contributions}

YMY and $\mathrm{HH}$ conceptualized and designed the study. YMY acquired and analyzed the data. YMY, BCS, and CS interpreted the results. YMY drafted the original article. YMY, BCS, CS, and IHH critically revised the draft. All authors have read and approved of the final version.

\section{Funding}

All authors have no source of funding

\section{Availability of data and materials}

The datasets used during this study are available from the corresponding author on reasonable request.

\section{Ethics approval and consent to participate}

This study was approved by the Institutional Review Board of Jaseng Hospital of Korean Medicine. Written informed consent was obtained from all study participants.

\section{Consent for publication}

Not applicable.

\section{Competing interests}

The authors declare that they have no competing interests.

\section{Author details}

'Department of Biomedical Informatics, Ajou University School of Medicine, 164, Worldcup-Ro, Yeongtong-gu, Suwon 16499, Korea. ${ }^{2}$ Department of Korean Rehabilitation Medicine, Pusan National University Korean Medicine Hospital, Yangsan, Republic of Korea. ${ }^{3}$ Department of Oriental Rehabilitation Medicine, National Rehabilitation Center, Seoul, Republic of Korea. ${ }^{4}$ Jaseng Spine and Joint Research Institute, Jaseng Medical Foundation, 3F JS Tower, 538 Gangnam-daero, Gangnam-gu, Seoul 06110, Republic of Korea.

Received: 27 February 2019 Accepted: 5 June 2019

Published online: 27 June 2019

\section{References}

1. Pucci G, Alcidi R, Tap L, Battista F, Mattace-Raso F, Schillaci G. Sex- and genderrelated prevalence, cardiovascular risk and therapeutic approach in metabolic syndrome: a review of the literature. Pharmacol Res. 2017;120:34-42.

2. Cho DY, Koo JW. Differences in metabolic syndrome prevalence by employment type and sex. Int J Environ Res Public Health. 2018;15(9). https://doi.org/10.3390/ijerph15091798.

3. Ranasinghe P, Mathangasinghe $Y$, Jayawardena R, Hills AP, Misra A. Prevalence and trends of metabolic syndrome among adults in the asiapacific region: a systematic review. BMC Public Health. 2017;17(1):101. https://doi.org/10.1186/s12889-017-4041-1.

4. Song OB, Zhao Y, Liu YQ, Zhang J, Xin SJ, Dong GH. Sex difference in the prevalence of metabolic syndrome and cardiovascular-related risk factors in urban adults from 33 communities of China: the CHPSNE study. Diab Vasc Dis Res. 2015;12(3):189-98.

5. Li Y, Zhao L, Yu D, Wang Z, Ding G. Metabolic syndrome prevalence and its risk factors among adults in China: a nationally representative crosssectional study. PLoS One. 2018;13(6):e0199293. https://doi.org/10.1371/ journal.pone.0199293. eCollection 2018.

6. Aguilar M, Bhuket T, Torres S, Liu B, Wong RJ. Prevalence of the metabolic syndrome in the United States, 2003-2012. JAMA. 2015;313(19):1973-4.

7. Lim S, Shin $\mathrm{H}$, Song JH, et al. Increasing prevalence of metabolic syndrome in Korea: the Korean National Health and nutrition examination survey for 1998-2007. Diabetes Care. 2011;34(6):1323-8.

8. Prasad DS, Kabir Z, Dash AK, Das BC. Prevalence and risk factors for metabolic syndrome in Asian Indians: a community study from urban eastern India. J Cardiovasc Dis Res. 2012;3(3):204-11.

9. Kim HR, Han MA. Association between serum liver enzymes and metabolic syndrome in Korean adults. Int J Environ Res Public Health. 2018;15(8). https://doi.org/10.3390/ijerph15081658.

10. Lee S, Ko Y, Kwak C, Yim ES. Gender differences in metabolic syndrome components among the Korean 66-year-old population with metabolic syndrome. BMC Geriatr. 2016;16:27. https://doi.org/10.1 186/s12877-016-0202-9.

11. Arai $\mathrm{H}$, Yamamoto A, Matsuzawa $\mathrm{Y}$, et al. Prevalence of the metabolic syndrome in elderly and middle-aged Japanese. J Clin Gerontol Geriatr. 2010;1:42-7.

12. Akbulut G, Köksal E, Bilici S, et al. Metabolic syndrome (MS) in elderly: a cross sectional survey. Arch Gerontol Geriatr. 2011;53(3):e263-6.

13. Lim ES, Ko YK, Ban KO. Prevalence and risk factors of metabolic syndrome in the Korean population--Korean National Health Insurance Corporation Survey 2008. J Adv Nurs. 2013;69(7):1549-61.

14. American Diabetes Association. Classification and diagnosis of diabetes: standards of medical care in diabetes - 2018. Diabetes Care. 2018:41(Suppl 1):S13-27.

15. National cholesterol education program expert panel on detection, evaluation, and treatment of high blood cholesterol in adults (adult treatment panel III). Available from: https://www.nhlbi.nih.gov/files/docs/ guidelines/atp3xsum.pdf. Accessed on 03 Dec 2018.

16. James PA, Oparil S, Carter BL, et al. 2014 evidence-based guideline for the management of high blood pressure in adults: report from the panel members appointed to the eighth joint National Committee (JNC 8). JAMA. 2014;311(5):507-20.

17. Expert Consultation WHO. Appropriate body-mass index for Asian populations and its implications for policy and intervention strategies. Lancet. 2004;363(9403):157-63.

18. Lee SY, Park HS, Kim DJ, et al. Appropriate waist circumference cutoff points for central obesity in Korean adults. Diabetes Res Clin Pract. 2007;75(1):72-80.

19. Ku PW, Steptoe A, Liao Y, Hsueh MC, Chen LJ. A cut-off of daily sedentary time and all-cause mortality in adults: a meta-regression analysis involving 
more than 1 million participants. BMC Med. 2018;16(1):74. https://doi.org/10, 1186/s12916-018-1062-2.

20. Krieger N. Genders, sexes, and health: what are the connections - and why does it matter? Int J Epidemiol. 2003;32(4):652-7.

21. EUGenMed Cardiovascular Clinical Study Group. Regitz-Zagrosek V, OerteltPrigione $\mathrm{S}$, et al. gender in cardiovascular diseases: impact on clinical manifestations, management, and outcomes. Eur Heart J. 2016;37(1):24-34.

22. Roh E, Ko SH, Kwon HS, et al. Prevalence and management of dyslipidemia in Korea: Korea National Health and nutrition examination survey during 1998 to 2010. Diabetes Metab J. 2013;37(6):433-49.

23. Song $\mathrm{Y}$, Joung $\mathrm{H}$. A traditional Korean dietary pattern and metabolic syndrome abnormalities. Nutr Metab Cardiovasc Dis. 2012;22(5):456-62.

24. Jung $\mathrm{CH}$, Choi KM. Impact of high-carbohydrate diet on metabolic parameters in patients with type 2 diabetes. Nutrients. 2017;9(4). https://doi. org/10.3390/nu9040322.

25. Nabuco HCG, Tomeleri CM, Sugihara Junior $P$, et al. Lower protein and higher carbohydrate intake are related with altering metabolic syndrome components in elderly women: a cross-sectional study. Exp Gerontol. 2018; 103:132-7.

26. Eftekhari MH, Sohrabi Z, Parsa N, Nezhad MJZ. Role of gender in the prevalence of metabolic syndrome and its related risk factors in shiraz healthy heart center population. Int Cardiovasc Res J. 2015;9(4):231-7.

27. Lasky D, Becerra E, Boto W, Otim M, Ntambi J. Obesity and gender differences in the risk of type 2 diabetes mellitus in Uganda. Nutrition. 2002; 18(5):417-21.

28. Mauvais-Jarvis F. Gender differences in glucose homeostasis and diabetes. Physiol Behav. 2018;187:20-3.

29. Liu J, Fox CS, Hickson DA, et al. Impact of abdominal visceral and subcutaneous adipose tissue on cardiometabolic risk factors: the Jackson heart study. J Clin Endocrinol Metab. 2010;95(12):5419-26.

30. Gambacciani M, Cagnacci A, Lello S. Hormone replacement therapy and prevention of chronic conditions. Climacteric. 2019:1-4. https://doi.org/10. 1080/13697137.2018.1551347 [Epub ahead of print].

31. Mauvais-Jarvis F, Manson JE, Stevenson JC, Fonseca VA. Menopausal hormone therapy and type 2 diabetes prevention: evidence, mechanisms, and clinical implications. Endocr Rev. 2017;38(3):173-88.

32. Navarro G, Allard C, Xu W, Mauvais-Jarvis F. The role of androgens in metabolism, obesity, and diabetes in males and females. Obesity (Silver Spring). 2015;23(4):713-9.

33. Bitoska I, Krstevska B, Milenkovic T, et al. Effects of hormone replacement therapy on insulin resistance in postmenopausal diabetic women. Open Access Maced J Med Sci. 2016;4(1):83-8.

34. Jones TH, Arver S, Behre HM, et al. Testosterone replacement in hypogonadal men with type 2 diabetes and/or metabolic syndrome (the TIMES2 study). Diabetes Care. 2011;34(4):828-37.

35. Hackett G, Cole N, Bhartia M, et al. Testosterone replacement therapy improves metabolic parameters in hypogonadal men with type 2 diabetes but not in men with coexisting depression: the BLAST study. J Sex Med. 2014;11(3):840-56

36. Sarganas G, Neuhauser HK. The persisting gender gap in hypertension management and control in Germany: 1998 and 2008-2011. Hypertens Res. 2016;39(6):457-66.

37. Mendelsohn ME. Protective effects of estrogen on the cardiovascular system. Am J Cardiol. 2002;89(12A):12E-7E discussion 17E-18E.

38. Pechère-Bertschi A, Burnier M. Female sex hormones, salt, and blood pressure regulation. Am J Hypertens. 2004;17(10):994-1001.

39. Williams CM. Lipid metabolism in women. Proc Nutr Soc. 2004;63(1):153-60.

40. Sironi AM, Gastaldelli A, Mari A, et al. Visceral fat in hypertension: influence on insulin resistance and beta-cell function. Hypertension. 2004;44(2):127-33.

41. Jiang J, Deng S, Chen Y, et al. Comparison of visceral and body fat indices and anthropometric measures in relation to untreated hypertension by age and gender among Chinese. Int J Cardiol. 2016;219:204-11.

\section{Publisher's Note}

Springer Nature remains neutral with regard to jurisdictional claims in published maps and institutional affiliations.

\section{Ready to submit your research? Choose BMC and benefit from:}

- fast, convenient online submission

- thorough peer review by experienced researchers in your field

- rapid publication on acceptance

- support for research data, including large and complex data types

- gold Open Access which fosters wider collaboration and increased citations

- maximum visibility for your research: over $100 \mathrm{M}$ website views per year

At BMC, research is always in progress.

Learn more biomedcentral.com/submissions 